\title{
A phase Ib, open-label, dose-escalation trial of the anti-CD37 monoclonal antibody, BI 836826, in combination with gemcitabine and oxaliplatin in patients with relapsed/refractory diffuse large B-cell lymphoma
}

\author{
Monica Balzarotti ${ }^{1}$ - Massimo Magagnoli ${ }^{1}$. Miguel Ángel Canales ${ }^{2} \cdot$ Paolo Corradini $^{3,4} \cdot$ Carlos Grande $^{5}$. \\ Juan-Manuel Sancho ${ }^{6}$. Francesco Zaja ${ }^{7}$. Anne-Marie Quinson ${ }^{8}$ - Valérie Belsack ${ }^{9}$. Daniela Maier ${ }^{10}$. \\ Carmelo Carlo-Stella ${ }^{1,11}$ iD
}

Received: 9 November 2020 / Accepted: 16 December 2020 / Published online: 1 February 2021

(C) The Author(s) 2021

\section{Summary}

Background BI 836826 is a chimeric mouse-human monoclonal antibody directed against human CD37, a transmembrane protein expressed on mature B lymphocytes. This open-label, phase I dose-escalation trial (NCT02624492) was conducted to determine the maximum tolerated dose (MTD), safety/tolerability, and preliminary efficacy of BI 836826 in combination with gemcitabine and oxaliplatin in patients with relapsed/refractory diffuse large B-cell lymphoma (DLBCL). Methods Eligible patients received intravenous infusions of BI 836826 on day 8 and gemcitabine $1000 \mathrm{mg} / \mathrm{m}^{2}$ plus oxaliplatin $100 \mathrm{mg} / \mathrm{m}^{2}$ on day 1, for up to six 14-day treatment cycles. Dose escalation followed the standard $3+3$ design. Results Of 21 treated patients, 17 had relapsed/refractory DLBCL and four had follicular lymphoma transformed to DLBCL. BI 836826 dosing started at $25 \mathrm{mg}$ and proceeded through $50 \mathrm{mg}$ and $100 \mathrm{mg}$. Two dose-limiting toxicities (DLTs) occurred during cycle 1, both grade 4 thrombocytopenia lasting $>7$ days, affecting $1 / 6$ evaluable patients $(17 \%)$ in both the $50 \mathrm{mg}$ and $100 \mathrm{mg}$ cohorts. Due to early termination of the study, the MTD was not determined. The most common adverse events related to BI 836826 treatment were neutropenia (52\%), thrombocytopenia (48\%), and anemia (48\%). Eight patients (38\%) experienced BI 836826-related infusionrelated reactions (two grade 3). Overall objective response rate was 38\%, including two patients (10\%) with complete remission and six patients (29\%) with partial remission. Conclusions BI 836826 in combination with GemOx was generally well tolerated but did not exceed the MTD at doses up to $100 \mathrm{mg}$ given every 14 days.

Keywords BI 836826 · CD37 · Diffuse large B-cell lymphoma · Non-Hodgkin lymphoma · Phase I · Relapsed

Carmelo Carlo-Stella

carmelo.carlostella@hunimed.eu

1 Oncology and Hematology Unit, Humanitas Cancer Center, Humanitas Clinical and Research Center - IRCCS, Rozzano, Milano, Italy

2 Servicio de Hematologia, Hospital Universitario La Paz, Madrid, Spain

3 University of Milan, Milan, Italy

4 Division of Hematology, Fondazione IRCCS Istituto Nazionale dei Tumori, Milan, Italy

5 Hospital Universitario 12 de Octubre, Madrid, Spain
6 Clinical Hematology Department, ICO-IJC-Hospital Germans Trias i Pujol, Badalona, Spain

7 University of Trieste, Ospedale Maggiore, Piazza dell'Ospitale 1, Trieste, Italy

8 Boehringer Ingelheim Pharmaceuticals, Inc, Ridgefield, CT, USA

9 SCS Boehringer Ingelheim Comm.V, Brussels, Belgium

10 Boehringer Ingelheim Pharma GmbH \& Co. KG, Biberach an der Riß, Germany

11 Department of Biomedical Sciences, Humanitas University, Milan, Italy 


\section{Introduction}

Diffuse large B-cell lymphoma (DLBCL) is the most common form of non-Hodgkin lymphoma (NHL) and accounts for approximately $30-40 \%$ of new NHL cases $[1,2]$. The current standard of care for front-line treatment of DLBCL is immunochemotherapy: rituximab plus the multi-agent chemotherapy cyclophosphamide, doxorubicin, vincristine, and prednisone (R-CHOP) [3]. Up to $40 \%$ of patients relapse or become refractory to R-CHOP. However, despite years of intensive research into alternative front-line treatments, $\mathrm{R}$ CHOP or R-CHOP-like therapies remain the standard of care. Poor response rates to front-line treatment have been associated with various prognostic factors, including clinical characteristic indices (International Prognosis Index [IPI], Revised-IPI [R-IPI], and NCCN-IPI) [4-6], high expression of certain tumor markers (e.g. $\beta 2$-microglobulin), molecular rearrangements of oncogenes (e.g. MYC, BCL2), or cell of origin classification (e.g. activated B-cell-like origin) [7, 8]. Patients who are refractory to, or relapse after, first-line immunochemotherapy generally receive high dose chemotherapy followed by autologous stem cell transplant (ASCT) $[9,10]$. However, outcomes following salvage treatment are generally poor. For instance, in the retrospective SCHOLAR1 study of 636 patients with refractory DLBCL, the response rate to subsequent therapy was only $26 \%$ with median overall survival (OS) of 6.3 months [11]. Moreover, anti-CD20 based immunochemotherapy regimens appear to have low efficacy in the salvage setting. In the phase III CORAL trial, 3-year event-free survival in patients with relapsed/refractory DLBCL treated with R-ICE (rituximab, ifosfamide, carboplatin, etoposide) or R-DHAP (rituximab, dexamethasone, cytarabine, cisplatin) was $37 \%$ overall and only $21 \%$ in patients previously treated with rituximab [12]. Only 50\% of patients could proceed to ASCT [13]. Thus, more effective salvage strategies for patients with relapsed or refractory disease after front-line immunochemotherapy are needed [2].

CD37 is a tetraspanin protein that is highly expressed on mature B lymphocytes and lymphoid neoplasms [14-16]. It appears to have multiple physiological functions, including regulation of apoptosis/survival signaling [17], B/T cell interaction [18], and T-cell proliferation [19]. Early clinical studies of anti-CD37 agents [20-22] have demonstrated that it is a viable therapeutic target in B cell NHL.

BI 836826 is a chimeric Fc-engineered immunoglobulin G1 (IgG1) monoclonal antibody directed against human CD37 [23]. In transgenic mice and cynomolgous monkeys, BI 836826 dose-dependently depleted peripheral B cells, and significantly suppressed tumor growth in a mouse B-cell lymphoma xenograft model [23]. In phase I studies, BI 836826 demonstrated acceptable tolerability and anti-tumor activity in patients with relapsed/refractory chronic lymphocytic leukemia (CLL) [24] and in patients with relapsed/refractory B-cell
NHL [25]. As gemcitabine and oxaliplatin (GemOx), with or without rituximab, is a treatment option in patients with ASCT-ineligible relapsed/refractory DLBCL [26, 27], we investigated the feasibility of combining BI 836826 and GemOx in this phase I, dose escalation study.

\section{Patients and methods}

\section{Patients}

Eligible patients were aged 18 years or older and had histologically confirmed relapsed/refractory DLBCL (including transformed follicular lymphoma). 'Relapsed' was defined as the appearance of any new lesion after attainment of an initial complete response (CR) and 'refractory' was defined as $<50 \%$ decrease in lesion size with prior anti-lymphoma treatment in the absence of new lesion development. All patients had previously been treated with an anti-CD20 monoclonal antibody in combination with anthracycline-containing chemotherapy and were either ineligible for high dose therapy and ASCT or had relapsed/progressed after an autologous/allogeneic stem cell transplant. Allogeneic stem cell transplant performed at least 6 months prior to study entry was permitted if patients did not require immunosuppressive treatment and had no evidence of active graft-versus-host disease. Patients were required to have Eastern Cooperative Oncology Group (ECOG) performance status of 0-2, acceptable organ function, and a screening CT scan with involvement of at least one bi-dimensional lesion/node of $>1.5 \mathrm{~cm}$.

Key exclusion criteria were: prior history of malignancy other than DLBCL; known central nervous system involvement; and receipt of anti-lymphoma treatment either within 14 days or, in the case of an investigational agent, less than five half-lives of the investigational drug, prior to the first dose of the current trial medication.

The study was conducted in accordance with the Declaration of Helsinki and Good Clinical Practice guidelines, and the study protocol was approved by the Institutional Review Boards or Independent Ethics Committees of all participating institutions. Written informed consent was obtained from all patients.

\section{Study design and treatment}

This was an open-label, multicenter phase $\mathrm{Ib}$ dose-escalation trial conducted to determine the maximum tolerated dose (MTD), safety/tolerability, and preliminary efficacy of BI 836826 in combination with GemOx in patients with relapsed/refractory DLBCL (NCT02624492). BI 836826 (starting dose of $25 \mathrm{mg}$ ) was administered as an intravenous infusion on day 8 of each 14-day cycle, while gemcitabine $\left(1000 \mathrm{mg} / \mathrm{m}^{2}\right)$ and oxaliplatin $\left(100 \mathrm{mg} / \mathrm{m}^{2}\right)$ were given intravenously on day 1 of each cycle. Patients received a maximum 
of six treatment cycles; each cycle could be delayed by up to 14 days in cases of toxicity.

Paracetamol, antihistamine and glucocorticoid premedication to mitigate infusion-related reactions (IRRs) was administered 30-120 minutes prior to all BI 836826 infusions. Supportive care including blood products and growth factors were permitted according to local guidelines; prophylactic anti-infective agents were also allowed. Dose escalation was conducted according to the standard $3+3$ design and was planned to continue until the MTD of BI 836926 in combination with GemOx was reached. BI 836826 dose increments of 50, 100, 150 and $200 \mathrm{mg}$ were planned.

\section{Study assessments}

The primary endpoints were the MTD and the number of patients with dose-limiting toxicities (DLTs) during the MTD evaluation period (cycle 1). The MTD was defined as the highest dose for which the number of patients with DLTs was no more than $17 \%$ during the MTD evaluation period (cycle 1).

DLTs included both non-hematologic and hematologic adverse events (AEs) considered related to any trial medication. This included any non-hematologic grade $\geq 3$ AEs except for: laboratory abnormalities that could be corrected with treatment within $48 \mathrm{~h}$; nausea, vomiting, or diarrhea that resolved within $48 \mathrm{~h}$ with adequate treatment; neuropathy considered related to oxaliplatin; or IRRs. Hematologic DLTs were: grade 4 neutropenia lasting $>7$ days despite growth factor support; any febrile neutropenia that did not resolve within $48 \mathrm{~h}$ with appropriate treatment; grade 4 thrombocytopenia lasting $>7$ days or grade $3 / 4$ thrombocytopenia with clinically significant bleeding; failure to recover platelets $\geq 75 \times 10^{9} / \mathrm{L}$ by 4 weeks after the start of the cycle; and failure to recover neutrophils $\geq 1.0 \times 10^{9} / \mathrm{L}$ by 4 weeks after start of the cycle. Other safety assessments included the incidence and severity of AEs graded according to the Common Toxicity Criteria for Adverse Events (CTCAE, version 4.0) and changes in laboratory parameters.

The secondary endpoint was investigator-assessed best overall response according to International Working Group criteria for non-Hodgkin lymphoma [28] with refined evaluation of the PET scan using the 5-point scale [29].Tumor size reduction was analyzed as best percentage change from baseline in the sum of the product of the longest perpendicular diameters (SPD) based on imaging data. Pharmacokinetic analysis was planned but was not conducted.

\section{Statistical methods}

No formal statistical testing was undertaken. The number of patients with DLTs and the best overall response was summarized by descriptive statistics.

\section{Results}

\section{Patients and treatment exposure}

Thirty-five patients were enrolled and 21 treated at seven centers in Belgium, Italy and Spain between March 10, 2016 and March 16, 2018. All patients were white and $48 \%$ were male (Table 1). Median age was 54.0 years (range 22 to 86), and $57 \%, 33 \%$ and $10 \%$ of patients had a baseline ECOG performance score of 0,1 and 2, respectively. Of the 21 patients, 17 (81\%) had pure DLBCL and four (19\%) had follicular lymphoma transformed to DLBCL. Lymphoma was considered relapsed for $33 \%$ of patients, refractory for $38 \%$, and progressive for $29 \%$. All patients had previously received systemic therapy, with most having received one, two, or four previous therapies $(33 \%, 29 \%$, and $29 \%$ of patients, respectively); $71 \%$ had progressed following the last therapy.

The best response to previous therapy was CR in five patients (23.8\%), partial remission (PR) in two patients $(9.5 \%)$, and stable disease (SD) in two patients $(9.5 \%) ; 10$ patients $(47.6 \%)$ had progressive disease (PD); the status of two patients $(9.5 \%)$ was unknown or missing. Important protocol deviations were noted for seven patients, three of whom had more than one protocol deviation: entrance criteria were not met for 6 patients (efficacyrelated criteria for four patients, trial diagnosis for one patient, and safety criteria for one patient), administration of trial medication was delayed for three patients, and prohibited medication was administered for one patient (Supplementary Table 1).

All 21 patients discontinued the trial, with10 patients $(48 \%)$ completing the maximum of six treatment cycles. Of the 11 patients who discontinued before completing six cycles, six (29\%) discontinued due to AEs, and 5 (24\%) discontinued due to disease progression. Two patients did not receive a complete infusion of BI 836826: one died of tumor lysis syndrome after a single dose of GemOx and did not receive any BI 836826, while a second had an interruption of the first BI 836826 infusion due to an IRR. This patient received $10 \mathrm{mg}$ out of $25 \mathrm{mg}$ BI 836826 and permanently discontinued trial drug.

\section{MTD and DLTs}

BI 836826 dosing in combination with GemOx started at $25 \mathrm{mg}$ and proceeded through $50 \mathrm{mg}$ and $100 \mathrm{mg}$ cohorts. Six patients were replaced and hence excluded from the MTD evaluation set. Two DLTs occurred during the MTD evaluation period (cycle 1), both grade 4 thrombocytopenia lasting $>7$ days, affecting one of six evaluable patients $(17 \%)$ in the $50 \mathrm{mg}$ dosing cohort, and one of six evaluable patients (17\%) in the $100 \mathrm{mg}$ cohort. Due to a strategic decision by the sponsor, the trial was prematurely discontinued, and no further patients were enrolled after the $100 \mathrm{mg}$ dose cohort. Consequently, the MTD of BI 836826 in combination with GemOx was not established. 
Table 1 Patient demographics

\begin{tabular}{|c|c|c|c|c|}
\hline & \multicolumn{4}{|c|}{ BI 836826 dose $^{a}$} \\
\hline & $\begin{array}{l}25 \mathrm{mg} \\
(n=5)\end{array}$ & $\begin{array}{l}50 \mathrm{mg} \\
(n=8)\end{array}$ & $\begin{array}{l}100 \mathrm{mg} \\
(n=8)\end{array}$ & $\begin{array}{l}\text { Total } \\
(N=21)\end{array}$ \\
\hline Male, $n(\%)$ & $1(20.0)$ & $4(50.0)$ & $5(62.5)$ & $10(47.6)$ \\
\hline \multicolumn{5}{|l|}{ Race, $n(\%)$} \\
\hline White & $5(100.0)$ & $8(100.0)$ & $8(100.0)$ & $21(100.0)$ \\
\hline Median age, years (range) & $77.0(22-86)$ & $51.0(41-78)$ & $53.5(42-77)$ & $54.0(22-86)$ \\
\hline \multicolumn{5}{|l|}{ ECOG PS at baseline, $n(\%)$} \\
\hline 0 & $5(100.0)$ & $4(50.0)$ & $3(37.5)$ & $12(57.1)$ \\
\hline 1 & 0 & $2(25.0)$ & $5(62.5)$ & $7(33.3)$ \\
\hline 2 & 0 & $2(25.0)$ & 0 & $2(9.5)$ \\
\hline \multicolumn{5}{|l|}{ Ann Arbor stage at screening, $n(\%)$} \\
\hline II & 0 & $1(12.5)$ & 0 & $1(4.8)$ \\
\hline III & 0 & $2(25.0)$ & $3(37.5)$ & $5(23.8)$ \\
\hline IV & $5(100.0)$ & $5(62.5)$ & $5(62.5)$ & $15(71.4)$ \\
\hline Mean time from first diagnosis, years (SD) & $4.4(3.8)$ & $5.1(7.5)$ & $2.9(3.7)$ & $4.1(5.4)$ \\
\hline Median number of prior therapies (range) & $2.0(1-4)$ & $2.0(1-4)$ & $3.0(1-6)$ & $2.0(1-6)$ \\
\hline \multicolumn{5}{|l|}{ Prior therapy, $n(\%)$} \\
\hline Radiotherapy & $2(40.0)$ & $1(12.5)$ & $1(12.5)$ & $4(19.0)$ \\
\hline Stem cell transplant & $2(40.0)$ & $2(25.0)$ & $3(37.5)$ & $7(33.3)$ \\
\hline Surgery & 0 & $2(25.0)$ & $1(12.5)$ & $3(14.3)$ \\
\hline Progression since last systemic therapy, $n(\%)$ & $5(100.0)$ & $7(87.5)$ & $3(37.5)$ & $15(71.4)$ \\
\hline
\end{tabular}

${ }^{\text {a }}$ Given every 14 days in combination with gemcitabine $1000 \mathrm{mg} / \mathrm{m}^{2}$ and oxaliplatin $100 \mathrm{mg} / \mathrm{m}^{2}$

ECOG PS Eastern Cooperative Oncology Group Performance Status, $S D$ standard deviation

\section{Safety}

All patients experienced at least one AE during the ontreatment period of the trial, most commonly neutropenia $(n=16[79 \%])$, thrombocytopenia $(n=15[71 \%])$ and anemia $(n=14[67 \%])$. Sixteen patients $(76 \%)$ experienced at least one AE deemed to be related to BI 836826 by the Investigator; the most frequent were (any grade/grade 3/4) neutropenia (52/38\%), anemia (48/29\%), thrombocytopenia (48/43\%; Table 2). Eight patients (38\%) experienced a treatment-related IRR, of which two $(10 \%)$ were grade 3 . Two patients (10\%) had grade 4 neutropenia and a concomitant infection; both infections were of grade 2 . One patient had grade 4 thrombocytopenia and concomitant bleeding, a single episode of grade 2 melena. The most common nonhematological AEs considered related to BI 836826 included pyrexia $(n=2[9.5 \%])$, asthenia $(n=2[9.5 \%])$, chills, cough, dizziness, nausea and vomiting (all $n=1$ [4.8\%]), which were either grade 1 or grade 2.

During the entire on-treatment period, seven patients experienced AEs that were consistent with the definition of a DLT. Thrombocytopenia (5 patients [24\%]) was the only event reported for more than two patients.Six patients experienced a total of eight AEs leading to permanent discontinuation of last study medication: thrombocytopenia (two cases), neutropenia, Aspergillus infection, pneumonia, decreased white blood cell count, IRR, and tumor lysis syndrome (one case each).

Overall, 12 patients were reported with serious AEs (57\%), of which only thrombocytopenia (4 patients [19\%]) and IRR (3 patients [14\%]) occurred in more than two patients. Three patients died during the study; however, no deaths were attributed to BI 836826 . The case of tumor lysis syndrome was considered related to GemOx as the patient had not yet received BI 836926; the remaining two deaths were attributed to disease progression and Aspergillus infection.

\section{Efficacy}

The objective response rate was $38 \%$, including two patients (10\%) with complete remission and six patients (29\%) with partial remission (Table 3). Six patients (29\%) experienced stable disease, and three patients (14\%) had progressive disease. Four patients did not have a response assessment. Patients with baseline and at least one post-baseline disease assessment were evaluated for best change in SPD from baseline in lymph nodes, or organ or extra-lymphatic nodules based on PET/CT scan. The median best percentage change was $-31.3 \%$ (range -100 to $41 \%$ ) for 15 patients with 
Table 2 AEs considered related to BI 836826 occurring in $\geq 2$ patients

\begin{tabular}{lll}
\hline & $\begin{array}{c}\text { Any-grade } \\
n(\%)\end{array}$ & $\begin{array}{l}\text { Grade 3/4 } \\
n(\%)\end{array}$ \\
\hline Any treatment-related AEs & $16(76.2)$ & $12(57.1)$ \\
Neutropenia & $11(52.4)$ & $10(47.6)$ \\
Anemia & $10(47.6)$ & $6(28.6)$ \\
Thrombocytopenia & $10(47.6)$ & $9(42.9)$ \\
Infusion-related reaction & $8(38.1)$ & $2(9.5)$ \\
Decreased white blood cell count & $7(33.3)$ & $7(33.3)$ \\
Increased AST & $2(9.5)$ & 0 \\
Increased GGT & $2(9.5)$ & $1(4.8)$ \\
Asthenia & $2(9.5)$ & 0 \\
Pyrexia & $2(9.5)$ & 0 \\
Decreased platelet count & $1(4.8)$ & $1(4.8)$ \\
Pancytopenia & $1(4.8)$ & $1(4.8)$ \\
Increased ALT & $1(4.8)$ & 0 \\
Chills & $1(4.8)$ & 0 \\
Cough & $1(4.8)$ & 0 \\
Dizziness & $1(4.8)$ & 0 \\
Hyperuricemia & $1(4.8)$ & 0 \\
Nausea & $1(4.8)$ & 0 \\
Vomiting & $1(4.8)$ & 0 \\
\hline
\end{tabular}

$A L T$ alanine aminotransferase, $A S T$ aspartate aminotransferase, GGT gammaglutamyl transferase

baseline lymph nodules and $-78 \%$ (range $-89 \%$ to $-28 \%$ ) for five patients with extra-lymphatic disease nodules. In one patient with baseline liver nodules, change from baseline was $-38 \%$, while two patients with baseline spleen nodules had changes of $-100 \%$ and $-45 \%$.

\section{Discussion}

In this phase I, dose-finding study in patients with relapsed/ refractory DLBCL, BI 836826 in combination with GemOx was generally well tolerated. The MTD was not established, as

Table 3 Best overall response in patients receiving BI 836826 plus GemOx

\begin{tabular}{lllll}
\hline \multicolumn{5}{c}{ BI 836826 dose } \\
\cline { 2 - 5 } Patients with response, $n(\%)$ & $\begin{array}{l}25 \mathrm{mg} \\
(n=5)\end{array}$ & $\begin{array}{l}50 \mathrm{mg} \\
(n=8)\end{array}$ & $\begin{array}{l}100 \mathrm{mg} \\
(n=8)\end{array}$ & $\begin{array}{l}\text { Total } \\
(n=21)\end{array}$ \\
\hline Complete remission & $1(20.0)$ & 0 & $1(12.5)$ & $2(9.5)$ \\
Partial remission & $2(40.0)$ & $3(37.5)$ & $1(12.5)$ & $6(28.6)$ \\
Stable disease & $2(40.0)$ & $1(12.5)$ & $3(37.5)$ & $6(28.6)$ \\
Progressive disease & 0 & $2(25.0)$ & $1(12.5)$ & $3(14.3)$ \\
Missing & 0 & $2(25.0)$ & $2(25.0)$ & $4(19.0)$ \\
\hline
\end{tabular}

GemOx gemcitabine $1000 \mathrm{mg} / \mathrm{m}^{2}$ and oxaliplatin $100 \mathrm{mg} / \mathrm{m}^{2}$ the trial was prematurely discontinued following the termination of the BI 836826 clinical development program. The MTD was not exceeded at the doses tested (50 and $100 \mathrm{mg}$ given every 14 days).

Adverse events associated with BI 836826 administration were predominantly hematological, which is to be expected in this population, and in keeping with prior studies of BI 836826 in patients with B-cell malignancies [24, 30]. Grade 3/4 hematological AEs were more common in this study than with BI 836826 monotherapy [24, 30], most likely due to the additive effect of GemOx. One DLT of grade 4 thrombocytopenia lasting $>7$ days was recorded in each of the $50 \mathrm{mg}$ and $100 \mathrm{mg}$ dosing cohorts. As CD37 has been identified on megakaryocytes and platelets [31,32], this may be the result of the direct action of BI 836826 on these cells, or may be related to the myelotoxic effects of gemcitabine and oxaliplatin [33,34]. It is possible that the myelosuppressive effect of combination therapy was exacerbated by administering BI 836826 on day 8 of each cycle, corresponding with the nadir of hematological toxicity due to GemOx. Therefore, hematological toxicity could potentially be less severe with an alternative treatment schedule. However, the tested treatment schedule was based on modelling that evaluated different timings for the BI 836826 and GemOx administrations. The modelling showed that dosing BI 836826 after GemOx at the cytopenia nadir would actually shorten hematological toxicity compared to administering the drugs together, which was predicted to deepen and extend the cytopenia. Of note, the overall incidence of treatment-related IRRs (any-grade, 38\%; grade 3/4,10\%) was lower than in a previous study of BI 836826 in patients with relapsed/ refractory chronic lymphocytic leukemia (any-grade, $70 \%$; grade $3 / 4,8 \%$ ) [24], and comparable to that seen in Caucasian patients with relapsed/refractory B-cell NHL (any-grade, 41\%; grade 3/4, 8\%) [30].

The overall response rate in this study was $38 \%$. Few published data on the use of GemOx alone in DLBCL are available for comparison. In a retrospective study of GemOx with/ without rituximab in 44 patients with relapsed/refractory aggressive lymphoma, overall response rate was $43 \%$, including $30 \%$ CR [27], while an overall response rate of $61 \%$, with $44 \%$ CR, was reported in a study of 49 patients with relapsed/refractory DLBCL who received rituximab plus GemOx [26]. However, considerable hematological toxicity was observed in both studies, with $73 \%$ of patients experiencing grade $\geq 3$ neutropenia and $44 \%$ experiencing grade 3 thrombocytopenia in the latter study.

Although the clinical development of BI 836826 has been terminated for strategic reasons, the findings from this study suggest that CD37-based therapy for DLBCL can be safely combined with established chemotherapy regimens. A number of anti-CD37 therapies are currently being investigated for the treatment of Bcell NHL [20-22, 35-37], including radioimmunotherapy. Of 
note, a phase $\mathrm{Ib}$ study of the novel agent lutetium (177Lu)lilotomabsatetraxetan (Betalutin $\left.{ }^{\circledR}\right)$ in ASCT-ineligible patients with relapsed/refractory DLBCL is currently in progress (NCT02658968), and results from this and other ongoing clinical trials may provide new hope for DLBCL patients faced with limited options.

Supplementary Information The online version contains supplementary material available at https://doi.org/10.1007/s10637-020-01054-6.

Acknowledgements We thank the patients, their families, and all of the investigators who participated in these studies. The authors were fully responsible for all content and editorial decisions, were involved at all stages of manuscript development, and have approved the final version.

Author contributions Anne-Marie Quinson, Valérie Belsack and Carmelo Carlo-Stella contributed to the study conception and design. Material preparation and data collection were performed by Monica Balzarotti, Massimo Magagnoli, Miguel Ángel Canales, Paolo Corradini, Carlos Grande, Juan-Manuel Sancho, Francesco Zaja and Carmelo Carlo-Stella. Data analysis were performed by Anne-Marie Quinson, Valérie Belsack and Daniela Maier. The first draft of the manuscript was written by Anne-Marie Quinson, Valérie Belsack, Monica Balzarotti and Carmelo Carlo-Stella. All authors commented on previous versions of the manuscript. All authors read and approved the final manuscript.

Funding The conduct of this research, study design, data collection, and analysis was financially supported by Boehringer Ingelheim. Medical writing assistance, funded by Boehringer Ingelheim, was provided by Lynn Pritchard, DPhil, of GeoMed, an Ashfield company, part of UDG Healthcare plc, during the preparation of this manuscript.

Data Availability The clinical study report (including appendices, but without line listings) and other clinical documents related to this study may be accessed on request. Prior to providing access, the documents and data will be examined, and, if necessary, redacted and de-identified to protect the personal data of study participants and personnel, and to respect the boundaries of the informed consent of the study participants. See https://trials.boehringer-ingelheim.com/data_sharing/sharing.html\# accordion-1-2 for further details. Bona fide, qualified scientific and medical researchers may request access to de-identified, analyzable patient-level study data, together with documentation describing the structure and content of the datasets. Researchers should use https:// clinicalstudydatarequest.com/ to request access to raw data from this study.

\section{Compliance with ethical standards}

Conflict of interest Miguel Ángel Canales received speaker honoraria from Amgen, Janssen, Roche, Sandoz, Takeda; consulting fees from Celgene, Gilead, iQone, Janssen, Karyopharm, Novartis, Roche, Sandoz, Sanofi; and support for CME from Gilead, Janssen, Novartis, Roche, Sandoz, Sanofi.

Paolo Corradini received honoraria as a lecturer from AbbVie, Amgen, Celgene, Gilead/Kite, Janssen, Jazz Pharmaceutics, Novartis, Roche, Sanofi, Sandoz, Takeda, and consulting fees from AbbVie, ADC Therapeutics, Amgen, Celgene, Daiichi Sankyo, Gilead, Incyte, Janssen, Kite, KiowaKirin, Novartis, Roche, Sanofi, Servier and Takeda.

Francesco Zaja received honoraria from Novartis, Amgen, Janssen, Takeda, Celgene, Abbvie, Roche, Mundipharma and Grifols.
Juan-Manuel Sancho received advisory council or committee fees from Roche, Gilead, Janssen, Celgene, Incyte, Celltrion, Novartis, and honoraria as a speaker from Roche, Gilead, Janssen, Celgene, Incyte, Takeda, Novartis, Sanofi and Servier.

Anne-Marie Quinson, Valérie Belsack and Daniela Maier are employees of Boehringer Ingelheim.

Carmelo Carlo-Stella received honoraria from Bristol-Myers Squibb, Merck Sharp \& Dohme, Servier, Amgen, Janssen Oncology, Sanofi, ADC Therapeutics, Novartis, and AstraZeneca; provided consultancy to Boehringer Ingelheim, Genenta Science, Sanofi, ADC Therapeutics, and received research funding from Rhizen Pharmaceuticals.

Monica Balzarotti, Massimo Magagnoli and Carlos Grande report no conflict of interest.

Ethical approval All procedures performed in studies involving human participants were in accordance with the ethical standards of the institutional and/or national research committee and with the 1964 Helsinki declaration and its later amendments or comparable ethical standards.

Informed consent Informed consent was obtained from all individual participants included in the study.

Open Access This article is licensed under a Creative Commons Attribution 4.0 International License, which permits use, sharing, adaptation, distribution and reproduction in any medium or format, as long as you give appropriate credit to the original author(s) and the source, provide a link to the Creative Commons licence, and indicate if changes were made. The images or other third party material in this article are included in the article's Creative Commons licence, unless indicated otherwise in a credit line to the material. If material is not included in the article's Creative Commons licence and your intended use is not permitted by statutory regulation or exceeds the permitted use, you will need to obtain permission directly from the copyright holder. To view a copy of this licence, visit http://creativecommons.org/licenses/by/4.0/.

\section{References}

1. Li S, Young KH, Medeiros LJ (2018) Diffuse large B-cell lymphoma. Pathology 50(1):74-87. https://doi.org/10.1016/j.pathol.2017. 09.006

2. Sehn LH, Gascoyne RD (2015) Diffuse large B-cell lymphoma: optimizing outcome in the context of clinical and biologic heterogeneity. Blood 125(1):22-32. https://doi.org/10.1182/blood-201405-577189

3. Coiffier B, Lepage E, Briere J, Herbrecht R, Tilly H, Bouabdallah R, Morel P, Van Den Neste E, Salles G, Gaulard P, Reyes F, Lederlin P, Gisselbrecht C (2002) CHOP chemotherapy plus rituximab compared with CHOP alone in elderly patients with diffuse large-B-cell lymphoma. N Engl J Med 346(4):235-242. https://doi. org/10.1056/NEJMoa011795

4. Project IN-HsLPF (1993) A predictive model for aggressive nonHodgkin's lymphoma. N Engl J Med 329(14):987-994. https://doi. org/10.1056/nejm199309303291402

5. Sehn LH, Berry B, Chhanabhai M, Fitzgerald C, Gill K, Hoskins P, Klasa R, Savage KJ, Shenkier T, Sutherland J, Gascoyne RD, Connors JM (2007) The revised International Prognostic Index (R-IPI) is a better predictor of outcome than the standard IPI for patients with diffuse large B-cell lymphoma treated with R-CHOP. Blood 109(5):1857-1861. https://doi.org/10.1182/blood-2006-08038257 
6. Zhou Z, Sehn LH, Rademaker AW, Gordon LI, Lacasce AS, Crosby-Thompson A, Vanderplas A, Zelenetz AD, Abel GA, Rodriguez MA, Nademanee A, Kaminski MS, Czuczman MS, Millenson M, Niland J, Gascoyne RD, Connors JM, Friedberg JW, Winter JN (2014) An enhanced International Prognostic Index (NCCN-IPI) for patients with diffuse large B-cell lymphoma treated in the rituximab era. Blood 123(6):837-842. https://doi.org/ 10.1182/blood-2013-09-524108

7. Coiffier B, Sarkozy C (2016) Diffuse large B-cell lymphoma: RCHOP failure-what to do? Hematol Am Soc Hematol Educ Program 2016(1):366-378. https://doi.org/10.1182/asheducation2016.1.366

8. Younes A (2016) Promising novel agents for aggressive B-cell lymphoma. Hematol Oncol Clin North Am 30(6):1229-1237. https://doi.org/10.1016/j.hoc.2016.07.007

9. Skrabek P, Assouline S, Christofides A, MacDonald D, Prica A, Sangha R, Matthews BA, Sehn LH (2019) Emerging therapies for the treatment of relapsed or refractory diffuse large B cell lymphoma. Curr Oncol 26(4):253-265. https://doi.org/10.3747/co.26.5421

10. Coccaro N, Anelli L, Zagaria A, Perrone T, Specchia G, Albano F (2020) Molecular complexity of diffuse large B-Cell lymphoma: can it be a roadmap for precision medicine? Cancers (Basel) 12(1):185. https://doi.org/10.3390/cancers12010185

11. Crump M, Neelapu SS, Farooq U, Van Den Neste E, Kuruvilla J, Westin J, Link BK, Hay A, Cerhan JR, Zhu L, Boussetta S, Feng L, Maurer MJ, Navale L, Wiezorek J, Go WY, Gisselbrecht C (2017) Outcomes in refractory diffuse large B-cell lymphoma: results from the international SCHOLAR-1 study. Blood 130(16):1800-1808. https://doi.org/10.1182/blood-2017-03-769620

12. Gisselbrecht C, Glass B, Mounier N, Singh Gill D, Linch DC, Trneny M, Bosly A, Ketterer N, Shpilberg O, Hagberg H, Ma D, Brière J, Moskowitz CH, Schmitz N (2010) Salvage regimens with autologous transplantation for relapsed large B-cell lymphoma in the rituximab era. J Clin Oncol 28(27):4184-4190. https://doi.org/ 10.1200/jco.2010.28.1618

13. Gisselbrecht C, Van Den Neste E (2018) How I manage patients with relapsed/refractory diffuse large B cell lymphoma. Br J Haematol 182(5):633-643. https://doi.org/10.1111/bjh.15412

14. Elfrink S, de Winde CM, van den Brand M, Berendsen M, Roemer MGM, Arnold F, Janssen L, van der Schaaf A, Jansen E, Groenen P, Eijkelenboom A, Stevens W, Hess CJ, van Krieken JH, Vermaat JSP, Cleven AHG, de Groen RAL, Neviani V, de Jong D, van Deventer S, Scheijen B, van Spriel AB (2019) High frequency of inactivating tetraspanin C D37 mutations in diffuse large B-cell lymphoma at immune-privileged sites. Blood 134(12):946-950. https://doi.org/10.1182/blood.2019001185

15. Bertoni F, Stathis A (2016) Staining the target: CD37 expression in lymphomas. 128(26):3022-3023. https://doi.org/10.1182/blood2016-11-748137

16. Barrena S, Almeida J, Yunta M, Lopez A, Fernandez-Mosteirin N, Giralt M, Romero M, Perdiguer L, Delgado M, Orfao A, Lazo PA (2005) Aberrant expression of tetraspanin molecules in B-cell chronic lymphoproliferative disorders and its correlation with normal B-cell maturation. Leukemia 19(8):1376-1383. https://doi.org/ 10.1038/sj.leu.2403822

17. Lapalombella R, Yeh YY, Wang L, Ramanunni A, Rafiq S, Jha S, Staubli J, Lucas DM, Mani R, Herman SE, Johnson AJ, Lozanski A, Andritsos L, Jones J, Flynn JM, Lannutti B, Thompson P, Algate P, Stromatt S, Jarjoura D, Mo X, Wang D, Chen CS, Lozanski G, Heerema NA, Tridandapani S, Freitas MA, Muthusamy N, Byrd JC (2012) Tetraspanin CD37 directly mediates transduction of survival and apoptotic signals. Cancer Cell 21(5):694-708. https://doi.org/ 10.1016/j.ccr.2012.03.040

18. Knobeloch KP, Wright MD, Ochsenbein AF, Liesenfeld O, Lohler J, Zinkernagel RM, Horak I, Orinska Z (2000) Targeted inactivation of the tetraspanin CD37 impairs T-cell-dependent B-cell response under suboptimal costimulatory conditions. Mol Cell Biol 20(15):5363-5369

19. van Spriel AB, Puls KL, Sofi M, Pouniotis D, Hochrein H, Orinska Z, Knobeloch KP, Plebanski M, Wright MD (2004) A regulatory role for CD37 in T cell proliferation. J Immunol 172(5):2953-2961

20. Pagel JM, Spurgeon SE, Byrd JC, Awan FT, Flinn IW, Lanasa MC, Eisenfeld AJ, Stromatt SC, Gopal AK (2015) Otlertuzumab (TRU016), an anti-CD37 monospecific ADAPTIR therapeutic protein, for relapsed or refractory NHL patients. Br J Haematol 168(1):38 45. https://doi.org/10.1111/bjh.13099

21. Stathis A, Flinn IW, Madan S, Maddocks K, Freedman A, Weitman S, Zucca E, Munteanu MC, Lia Palomba M (2018) Safety, tolerability, and preliminary activity of IMGN529, a CD37-targeted antibody-drug conjugate, in patients with relapsed or refractory B-cell non-Hodgkin lymphoma: a dose-escalation, phase I study. Invest New Drugs 36(5):869-876. https://doi.org/10.1007/s10637-0180570-4

22. Sawas A, Savage KJ, Perez RP, Advani RH, Zaine JM, Lackey JM et al (2017) A phase 1 study of the anti-CD37 antibody-drug conjugate AGS67E in advanced lymphoid malignancies. Interim results. Presented at the 14th International Conference on Malignant Lymphoma, Lugano, Switzerland, 14-17 June, 2017. Hematol Oncol 35(Issue S2):49-49

23. Heider KH, Kiefer K, Zenz T, Volden M, Stilgenbauer S, Ostermann E, Baum A, Lamche H, Kupcu Z, Jacobi A, Muller S, Hirt U, Adolf GR, Borges E (2011) A novel Fc-engineered monoclonal antibody to CD37 with enhanced ADCC and high proapoptotic activity for treatment of B-cell malignancies. Blood 118(15):4159-4168. https://doi.org/10.1182/blood-2011-04351932

24. Stilgenbauer S, Aurran Schleinitz T, Eichhorst B, Lang F, Offner F, Rossi JF, Schroyens W, Van Den Neste E, Ysebaert L, von Wangenheim U, Ursula Kress U, Blum P, Zenz T (2019) Phase 1 first-in-human trial of the anti-CD37 antibody BI 836826 in relapsed/refractory chronic lymphocytic leukemia. Leukemia 33(10):2531-2535. https://doi.org/10.1038/s41375-019-0475-z

25. Kroschinsky F, Middeke JM, Janz M, Lenz G, Witzens-Harig M, Bouabdallah R, La Rosée P, Viardot A, Salles G, Kim SJ, Kim TM, Ottmann O, Chromik J, Quinson AM, von Wangenheim U, Burkard U, Berk A, Schmitz N (2020) Phase I dose escalation study of BI 836826 (CD37 antibody) in patients with relapsed or refractory B-cell non-Hodgkin lymphoma. Invest New Drugs 8(5):14721482. https://doi.org/10.1007/s10637-020-00916-3

26. Mounier N, El Gnaoui T, Tilly H, Canioni D, Sebban C, Casasnovas RO, Delarue R, Sonet A, Beaussart P, Petrella T, Castaigne S, Bologna S, Salles G, Rahmouni A, Gaulard P, Haioun C (2013) Rituximab plus gemcitabine and oxaliplatin in patients with refractory/relapsed diffuse large B-cell lymphoma who are not candidates for high-dose therapy. A phase II Lymphoma Study Association trial. Haematologica 98(11):17261731. https://doi.org/10.3324/haematol.2013.090597

27. Dhanapal V, Gunasekara M, Lianwea C, Marcus R, De Lord C, Bowcock S, Devereux S, Patten P, Yallop D, Wrench D, Fields P, Kassam S (2017) Outcome for patients with relapsed/refractory aggressive lymphoma treated with gemcitabine and oxaliplatin with or without rituximab; a retrospective, multicentre study. Leuk Lymphoma 58(9):1-9. https://doi.org/10.1080/10428194.2016. 1276288

28. Cheson BD, Pfistner B, Juweid ME, Gascoyne RD, Specht L, Horning SJ, Coiffier B, Fisher RI, Hagenbeek A, Zucca E, Rosen ST, Stroobants S, Lister TA, Hoppe RT, Dreyling M, Tobinai K, Vose JM, Connors JM, Federico M, Diehl V (2007) Revised response criteria for malignant lymphoma. J Clin Oncol 25(5):579586. https://doi.org/10.1200/JCO.2006.09.2403

29. Cheson BD, Fisher RI, Barrington SF, Cavalli F, Schwartz LH, Zucca E, Lister TA (2014) Recommendations for initial evaluation, 
staging, and response assessment of Hodgkin and non-Hodgkin lymphoma: the Lugano classification. J Clin Oncol 32(27):30593068. https://doi.org/10.1200/JCO.2013.54.8800

30. Kroschinsky F, Pezzutto A, Witzens-Harig M, Bouabdallah R, La Rosée P, Straube C, Viardot A, Schmitz N, Salles G, Dillenburger S, Russell C, Veau C, von Wangenheim U, Ottmann O (2015) Phase I dose-escalation study of BI 836826 in patients (pts) with relapsed or refractory non-Hodgkin lymphoma (NHL) of B cell origin. Hematol Oncol 33(S1):Abstract286. https://doi.org/10. 1007/s10637-020-00916-3

31. Protty MB, Watkins NA, Colombo D, Thomas SG, Heath VL, Herbert JM, Bicknell R, Senis YA, Ashman LK, Berditchevski F, Ouwehand WH, Watson SP, Tomlinson MG (2009) Identification of Tspan9 as a novel platelet tetraspanin and the collagen receptor GPVI as a component of tetraspanin microdomains. Biochem $\mathrm{J}$ 417(1):391-400. https://doi.org/10.1042/BJ20081126

32. Burkhart JM, Vaudel M, Gambaryan S, Radau S, Walter U, Martens L, Geiger J, Sickmann A, Zahedi RP (2012) The first comprehensive and quantitative analysis of human platelet protein composition allows the comparative analysis of structural and functional pathways. Blood 120(15):e73-e82. https://doi.org/10.1182/ blood-2012-04-416594

33. Alcindor T, Beauger $N$ (2011) Oxaliplatin: a review in the era of molecularly targeted therapy. Curr Oncol 18(1):18-25. https://doi. org/10.3747/co.v18i1.708

34. Cassidy CA, Peterson P, Cirera L, Roychowdhury DF (2001) Incidence of thrombocytopenia with gemcitabine-based therapy and influence of dosing and schedule. Anticancer Drugs 12(4): 383-385. https://doi.org/10.1097/00001813-200104000-00012

35. Scarfo I, Ormhoj M, Frigault MJ, Castano AP, Lorrey S, Bouffard AA, van Scoyk A, Rodig SJ, Shay AJ, Aster JC, Preffer FI, Weinstock DM, Maus MV (2018) Anti-CD37 chimeric antigen receptor $\mathrm{T}$ cells are active against B- and T-cell lymphomas. Blood 132(14):1495-1506. https://doi.org/10.1182/blood-2018-04-842708

36. Kolstad A, Madsbu U, Beasley M, Bayne M, Illidge TM, O’Rourke N, Lagerlöf I, Hajek R, Jurczak W, Willenbacher E, Fagerli UM, Obr A, Blakkisrud J, Muftuler Løndalen A, Rojkjaer L, Østengen Å, Bolstad N, Spetalen S, Erlanson M, Galleberg R, Nygaard Rudå S, Holte H (2018) LYMRIT 37 - 01: a phase i/ii study of 177lulilotomab satetraxetan (betalutin ${ }^{\circledR}$ ) antibody-radionuclideconjugate (ARC) for the treatment of relapsed non-hodgkin's lymphoma (NHL) - Analysis with 6-month follow-up. Blood 132(Suppl 1):2879-2879. https://doi.org/10.1182/blood-2018-99110555

37. Maaland AF, Heyerdahl H, O'Shea A, Eiriksdottir B, Pascal V, Andersen JT, Kolstad A, Dahle J (2019) Targeting B-cell malignancies with the beta-emitting anti-CD37 radioimmunoconjugate (177)Lu-NNV003. Eur J Nucl Med Mol Imaging 46(11):2311-2321. https://doi.org/10.1007/ s00259-019-04417-1

Publisher's note Springer Nature remains neutral with regard to jurisdictional claims in published maps and institutional affiliations. 